Portland State University

PDXScholar

\title{
Taking High-Impact Practices to Scale in Capstone and Peer Mentor Programs, and Revising University Studies' Diversity Learning Goal
}

Óscar Fernández

Portland State University, osf@pdx.edu

Dana Lundell

Portland State University, dlundell@pdx.edu

Seanna M. Kerrigan

Portland State University, kerrigs@pdx.edu

Follow this and additional works at: https://pdxscholar.library.pdx.edu/studies_fac

Part of the Curriculum and Social Inquiry Commons, Educational Assessment, Evaluation, and Research Commons, and the Scholarship of Teaching and Learning Commons Let us know how access to this document benefits you.

\section{Citation Details}

Fernández, Ó, Lundell, D., \& Kerrigan, S. (2018). Taking High-Impact Practices to Scale in Capstone and Peer Mentor Programs, and Revising University Studies' Diversity Learning Goal. The Journal of General Education, 67(3-4), 269-289. doi:10.5325/jgeneeduc.67.3-4.0269

This Article is brought to you for free and open access. It has been accepted for inclusion in University Studies Faculty Publications and Presentations by an authorized administrator of PDXScholar. Please contact us if we can make this document more accessible: pdxscholar@pdx.edu. 


\title{
Taking High-Impact Practices to Scale in Capstone and Peer Mentor Programs, and Revising University Studies' Diversity Learning Goal
}

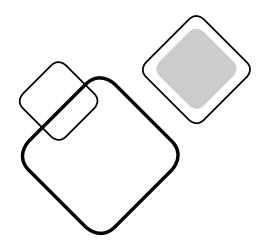

\author{
ÓSCAR FERNÁNDEZ, DANA LUNDELL, AND SEANNA KERRIGAN
}

ABSTRACT | University Studies, Portland State University's general education program, is now more than twenty years old; its leaders frequently answer questions from other higher education institutions regarding how the program takes high-impact practices to scale. In this article, three program leaders detail how University Studies' Peer Mentor and Senior Capstone Programs and one recently revised diversity learning goal demonstrate the opportunities and challenges of taking high-impact practices to scale. This article used published assessments of the program, experiences by current program leaders, and interviews from faculty members and peer mentors. Overall, the coauthors conclude that three dynamic qualities contribute to a scaling up of its programs and curricular initiatives: (1) focus on University Studies' aspirational goals; (2) interplay between scaling up and scaling inward-acknowledging the agency of its teaching and learning community to address challenges and effect change; and (3) collaborative and engaged leadership. These findings suggest that, contrary to notions that running a program of this scale only addresses budgets and staffing needs, University Studies adapts to change because it built a dynamic and aspirational framework across its general education program.

The longevity and scale of University Studies, Portland State University's general education program, attests to the resiliency of the program's vision, mission, and teaching ethos. Several critical elements fuel the ability of the program to scale up in terms of its growth over time: overt incorporation and fostering of its 
human capacities; collaborative work by leaders across its many program levels; and University Studies' teaching and learning community itself. The coauthors propose that the following are three dynamic qualities of University Studies that contribute to a successful, continuous, and often challenging, scaling up of its programs and curricular initiatives:

1. Focus on University Studies' mission, vision, teaching ethos, learning goals, and culture of assessment, and alignment of programs with, and intentionally examined through, University Studies' aspirational goals situated within changing social and cultural contexts;

2. Interplay between scaling up and scaling inward-meaning that program leaders recognize the agency of our human strengths in University Studies' teaching and learning community to address challenges and effect change; and,

3. Collaborative and engaged leadership defined by active listening, imagination, and thoughtful actions with support and feedback from the University Studies community.

While many aspects of University Studies share most of these qualities, each program level is unique and dynamically challenges the others. Taking our programs and aspirations to scale over time reflects the interrelationship of these qualities in University Studies. In this article, the coauthors will explore these three qualities as they operate at the Senior Capstone and Peer Mentor Program levels, which were implemented at the start of University Studies, as well as in the recent revision of the program's diversity learning goal, now known as our Diversity, Equity, and Social Justice (DESJ) learning goal.

\section{Taking High-Impact Practices to Scale: The Capstone Program}

I (coauthor Kerrigan) have served as the first and only Capstone Program Director since 1995 when Portland State University began to collaboratively build our Capstone Program in close partnerships with our community. The Capstone Program has flourished over the past two decades and serves as a national model; it engages students from every major at the institution (not a select subset), keeps equity and social justice as our central values, actively engages in reciprocal partnerships with our community, provides robust faculty support programming, and uses assessment for continuous improvement.

\section{History}

In 1994, when Portland State University revised its general education curriculum from a distribution structure into a four-year inquiry-based model, 
the program founders determined that a student's general education would now culminate in a required 6-credit community-based Senior Capstone course. Initially serving 2,00o students a year and making it the largest known community-based capstone program in the nation, Portland State University's Capstone faced its first challenge: generating 200 high-quality academic seminars, all of which would directly address real-world issues through partnerships within our communities. The purpose of Capstone courses was to prepare graduates for employment and community activism. By engaging interdisciplinary teams of students in the community to address genuine community needs, Capstones address the explicit learning goals of our general education program: Communication; Ethics and Social Responsibility; Inquiry and Critical Thinking; and Diversity, Equity, and Social Justice (formerly called the Diversity of the Human Experience). Clearly, the new inquiry-based Capstone requirement would require several explicit transformations at Portland State University.

1. Faculty would be asked to evolve their teaching practices to collaborate with community partners.

2. Students would be expected to shift from learning passively to adopting an engaged approach with their peers and in the community.

3. Faculty and students would be required to build authentic and reciprocal community-university partnerships that enhanced student learning as well as delivered value to community partners, as defined by the community.

4. Faculty would be invited to address power dynamics in the classroom (among the faculty members and students) and with community partners while modeling principles of equity in ways that encouraged community partners and students to become co-teachers in the learning process.

Also, faculty would need new sources and forms of support to catalyze learning experiences punctuated, at times, by unpredictable elements: working productively with community partners, facilitating effective interdisciplinary teams, and grading collaboratively while developing final products designed to meet the stated needs of the community partners.

\section{Scaling Up}

To bring this program to scale, we worked diligently and relationally to build Capstone infrastructure (e.g., faculty recruitment, community partnerships, and administrative procedures and processes) and Capstone courses. 
In 1995, Portland State University received a \$250,000 contribution from an anonymous donor that University Studies used as seed money for an internal Request for Proposals (RFP) that went to departments. In our RFP, we asked departments (not individual faculty) to collaborate with community organizations in proposing large-scale community partnerships through which multiple Capstone courses could be implemented. In one such case, Public Administration proposed a partnership with Portland's Bureau of EnvironmentalServices (BES), which established a long-term community-university partnership. Through this partnership, University Studies received the assurance that numerous Capstone course offerings would be implemented annually, with the additional curricular benefit of an ever-deepening partnership yielding meaningful opportunities for student engagement and community benefit.

Ultimately this RFP process funded about ten large-scale proposals across units throughout the University, resulting in the development of our first Capstones. The process generated partnerships that were sustainable, with many persisting over several years and some for over a decade. In the first year, we piloted five Capstone courses, studied them, learned what worked, and discovered the challenges encountered by faculty, students, and community partners. In the second year, we launched 25 additional Capstones, primarily through the partnerships developed in the RFP process. In the third year, we scaled up to 50 Capstones. By the year 2000, we had about 200 Capstone courses engaging nearly 2,00o students annually. Due to enrollment growth and budget limitations in the last decade, the Capstone program now serves over 4,00o students annually in approximately 240 Capstone courses.

\section{Scaling Inward: Building a Culture of Invitation, Trust, and Inclusion}

Although the initial process to develop Capstones required that funded proposals generate partnerships with the capacity for multiple and recurring Capstones, not all of our initial community partners came from large-scale community organizations. The values surrounding the importance of collaboration that emerged through the relationships with large and small-scale organizations formed and informed the program during this time and still holds today. The Capstone Program continues to encourage long-term, authentic, reciprocal partnerships based on principles of equity and the pursuit of social justice. These values are explicitly and formally addressed through a structured Capstone course approval process that requires faculty to read a foundational article on critical community-based learning. Faculty then state within their proposal how they considered this approach to community-based teaching through three core principles: a social change orientation, an effort to redistribute power, and the development of authentic relationships with community partners (Mitchell, 2008). The Capstone Program offers ongoing faculty 
development throughout the year to reinforce faculty members' understanding and skills to incorporate this approach.

Back in 1995, another critical consideration in bringing Capstones to scale was who the faculty for these dynamic courses would be. How would we develop strong teaching and learning communities with faculty who were new to teaching Capstones in a university setting? Since the beginning - and continuing today-faculty members at every rank and of every kind of employment status teach Capstones. Perhaps our biggest surprise regarding faculty involvement was how successful adjunct faculty were in teaching Capstone courses. Though many of our early Capstone adjunct faculty often had little experience in higher education, they possess the perfect skill set to facilitate transformative learning experiences for our students. Over the past two decades, Capstone students in our course evaluations commonly share how deeply they appreciate the varied professional experiences of our faculty from outside the academy. As one student remarked, "I feel as if the instructor's lived and work experience helped me conceptualize the information in the course" (Capstone, 2018). Another student stated in the end of term course evaluation that the most important learning came from the "specific firsthand experience of the instructor as an attorney" (Capstone, 2018). In retrospect, it makes perfect sense that community professionals with $20+$ years of experience in facilitation, conflict resolution, team building, diversity training, project management, environmental sciences, and human services would be well positioned to facilitate deep learning and difficult dialogues as they helped students unpack the complexities of interlocking systems of oppression, power, and privilege, while respectfully engaging participants across difference.

\section{Focus on University Studies' Culture of Assessment}

After building the infrastructure, curricular vision, and community of faculty for the program, our next challenge was developing a robust assessment plan. (Kerrigan \& Jhaj [2007] detail our comprehensive approach to assessment; Carpenter and Fitzmaurice's article in this issue also address the program's assessment practices.) When they join our program, faculty learn that assessment of Capstone courses is a form of ongoing programmatic improvement, not an administrative process to impact the employment of faculty.

Knowing that it was imperative to set up a culture of assessment for continuous improvement, faculty and administrators studied and assessed our Capstones and community-based learning courses in those early years. Our most significant learning, demonstrated through extensive interviews with students, was that Capstones needed to explicitly address diversity and equity issues with more deliberation and care. In our early Capstones and community-based 
learning courses, students were clearly expressing fears, concerns, and biases that impacted their collaborations in the community (Kerrigan, Gelmon, \& Spring, 2003). For example, one student stated "I didn't know that area [of Portland]-I wasn't use [sic] to it. There was some fear of that area. I was really nervous about the whole thing" (Kerrigan, Gelmon, Spring, p. 59). Additional students expressed concern for their "personal safety," "survival," and their personal belongings. Finally, one student admitted, "the danger is not necessarily in the community, the fear is in me" (Kerrigan, Gelmon, \& Spring, p. 59). We knew then that reflecting upon issues of diversity and equity would be essential in our program.

Assessment of our Capstones informed our staffing plan for the program and encouraged us to find the resources by 1997 to secure a faculty development support coordinator. The primary responsibility of that role was to support faculty in addressing diversity issues within our Capstone courses and our community partnerships. This position has changed titles and locations within our University from our former faculty development center (formerly called our Center for Academic Excellence) to now staffing this Faculty Development Coordinator role within our unit. Diversity, equity, and social justice work is the core bedrock of our faculty support programming and the signature element of our Capstone courses.

\section{Focus on University Studies' Learning Goals: Staying True to Our Interdisciplinary Community-based Seminar-style Capstone}

Over the last two decades, the University has engaged in an aggressive plan for enrollment growth, resulting in our now serving more than 4,000 seniors per year in Capstone courses. Due to economic limitations at our underfunded state institution, the 10-person class size that was typical in the earliest Capstone courses became unsustainable, and we resorted to raising class sizes in Capstones in response to budgetary pressures on University Studies. The Capstone program now enrolls between 4,000 and 4,400 students annually in about 240 Capstones-a similar course capacity that we had with 2,000 students. Maintaining the dynamic, transformational, and relational culture of Capstone courses while absorbing demands for larger class sizes remains one of the most significant current challenges within our program.

An additional challenge, which arose about 15 years after the launch of our original Capstones, is maintaining the University's commitment to interdisciplinary Capstones. In 2010, senior administrators decided to allow the University's School of Business Administration (SBA) to modify an existing SBA case-study course into a Senior Capstone. Now about 900 University students take this 40o-level SBA course to fulfill their general education Capstone. 
However, our assessment data demonstrates that these discipline-based Capstones neither facilitate the same transformative learning experience nor address the University Studies learning goals at the same depth as interdisciplinary Capstones. We attempted to address the challenges in our SBA Capstones by providing extensive faculty support for enhanced teaching and learning as well as deepening the focus on the University Studies' learning goals. Unfortunately, structural issues with this discipline-specific Capstone including class sizes that typically number 36 students and an intensive focus on academic course content rather than two of our learning goals (Social Responsibility and Diversity, Equity, and Social Justice) minimized any significant positive impact of these interventions within our School of Business Administration Capstones.

In closing, our Capstone Program acknowledges and publically reflects upon our challenges while continuing to serve as a national model of success for this high-impact practice. The American Association of Colleges and Universities (AAC\&U) highlighted the Portland State Capstone as an exemplar for Community-Engaged Signature Work (Ho \& Wolf, 2016). Our program engages students with "important unscripted real-world problems" which better prepares them for life after college and teaches students to collaboratively build more just communities (Ho \& Wolfe, p. 5).

We are most proud of the strength of our relationships with those who participate in our program: our students, our faculty, and our community partners. Our resiliency is based on having an active faculty learning community dedicated to diversity, equity, and social justice as well as our collaborative leadership, responsive listening, and imaginative thinking to resolve issues. We hold fast to our values of interdisciplinary teaching and learning and never lose sight of our goal: to co-create a just world.

\section{Taking High-Impact Practices to Scale: The Peer Mentor Program}

As program director since 2010, I (co-author Lundell) work collaboratively in support of the Peer Mentor Program. The Peer Mentor Program maintains a strong presence at Portland State University. Each year, I field many inquiries related to our work from colleges and universities around the country, specifically related to its scale and scope, which are especially unique in public higher education-and general education in particular.

\section{History}

The University's Peer Mentor Program is the largest mentoring program on campus and in the State, drawing from a range of disciplines, colleges, and 
majors to support the interdisciplinary nature of Freshmen Inquiry (FRINQ) and Sophomore Inquiry (SINQ) courses. The Peer Mentor Program exists to address campus-wide issues related to retention and support for transfer students (Collier, 2015; White, 1994). Twenty-four years since the mentor program's inception beginning with the first cohort of FRINQ mentors in 1994-95 and followed by the addition of SINQ mentors in 1995-96, the program still serves as one of the nation's largest curricular peer-mentoring programs in general education.

The significance of University Studies' incorporation of peer mentoring into the University's model of general education relates to the legacy of research on student development theory and college student adjustment and transition (Astin, 1997; Tinto, 1994), as well as the widespread and welldocumented practices of tutoring, peer mentoring, and supplemental instruction in higher education (Agee \& Hodges, 2012; Komives, et al., 2011). More than 20 years later, this research continues to demonstrate that peer mentoring, as one aspect of students' higher education experiences, measurably and positively increases their feelings of engagement both in and beyond the college classroom (Ray \& Kofka, 2014; Rivard, 2014). Research on issues of access, identity, social capital, belonging, diversity, and equity in higher education are also well documented, showing that peer mentoring programs positively benefit the success of students, particularly students of color, students with first-generation or low-income status, immigrant and refugee students, and students with disabilities (Collier, 2015, 2017; Smith, 2013; Weiston-Serdan, 2017).

\section{Scaling Up}

The University Studies Peer Mentor Program was initially built on a large scale across two levels of the base curriculum (Portland State University, 1998). The scale of the Peer Mentor Program then increased over time as the University expanded its campus enrollments, which required University Studies to increase the number of FRINQ and SINQ courses. When the Peer Mentor Program started in 1994-1995, 24 undergraduate peer mentors were hired for FRINQ courses. In the following year 1995-1996, University Studies added its first SINQ courses with a corresponding cohort of 19 graduate mentors. While enrollments grew in both FRINQ and SINQ, FRINQ mentors totaled 48 in Fall 2018, while SINQ mentors totaled 61 at the peak in 2015-2016 until costs of hiring graduate mentors resulted in hiring fewer mentors for still-growing numbers of SINQ courses. In Fall 2018, there were 72 SINQs while mentors declined to 38 total (because budgets necessitated that most SINQ mentors be required to mentor for double the number of classes). 
Up through AY 2018-19, each FRINQ and SINQ course requires one distinct mentor per course section, with mentors for FRINQ courses being upperdivision undergraduates (with 3 mentored sections of 12 students each meeting twice per week) and mentors for SINQ being graduate students (with 3 mentored sections of 12 students each meeting once per week). Both undergraduate and graduate students working as mentors receive tuition remission. Additionally, FRINQ mentors receive a monetary leadership award-similar to a small scholarship - and SINQ mentors are compensated with a stipend as employees.

The Peer Mentor Program's primary annual activities include mentor recruiting, hiring, supervising, and ongoing training to increase mentoring skills and outreach in University Studies FRINQ and SINQ courses. Overall, the program's positive impact on student success in FRINQ and SINQ courses is well documented in end-of-term course evaluations and through University Studies' various assessment efforts, which identify mentoring as one of the critical influences on students' perspectives of their growth and learning (University Studies Program, 2011b). Former graduate mentor program alum, mentor class of 2010, Phyusin Myint, offered this reflection:

The mentor program was ... critical to my development as a scholar, a faculty, and a student. I made lifelong friendships and connections with other students who continue to play a critical role in my life. It was also fundamental to my development as a teacher. My time as a mentor made me realized that I am deeply passionate about teaching. With every class, I reach out to each and every one of my students to build relevant and meaningful connections between the theory and practice. (P. Myint, personal communication, November 23, 2018)

Myint's comment echoes sentiments by undergraduate and graduate peer mentors that also report positive outcomes related to their work as University Studies mentors, including an increased sense of belonging and positive impacts on the development of their professional identity development (University Studies Program, 2011a).

\section{Scaling Inward: Mentor Program Opportunities and Successes}

This past academic year (2017-2018), University Studies' 103 Peer and Graduate Mentors worked collectively with 8,019 FRINQ and SINQ students. Our Peer Mentor Program frames the Program's mission at the curricular level in mentored inquiry sections led by peers, which contributes to the success of University Studies with its wrap-around curricular model that emphasizes its values 
of student-centered learning. The twofold effect of including peer mentors in classrooms, alongside faculty, exponentially increases the impact of peer learning, as mentors engage in self-reflection, professional development, and identity shifts from "student" to highly capable "peer-among-their-peers" over the course of a term (for SINQ mentors) or an academic year (for FRINQ mentors). Each year at graduation time, peer mentors offer anecdotes that employ the word "transformational" to describe what they got out of the peer-mentor experience. This peer mentor experience is immeasurable, certainly as yet an under-investigated aspect of the program.

Despite the distinct challenges of the Peer Mentor Program's scope and scale, the driving reason for our commitment to the program relates directly to University Studies' mission, vision, and realization of its progressive and studentcentered pedagogy. With modest program staffing for its size and relevancy in the University and University Studies curriculum, the Mentor Program intentionally embraces the presence and expert contributions of University Studies faculty, staff, and mentors. To be successful, the program scales inwardly to engage the diverse range of visions, campus partner, resources, and pedagogies for engaged learning. Everyone-not just the staff-is invited to care for and take responsibility for aspects of working with our mentors to support mentees.

University Studies' commitment to innovative and transformational teaching and learning also aligns with the Peer Mentor Program's focus on equity and social justice. University Studies' hiring of a Diversity, Equity, and Inclusion Coordinator, currently Dr. Óscar Fernández (coauthor), offers support for energizing new partnerships to strengthen the Peer Mentor Program's outreach and to attract, hire, and retain peer mentors from a diversity of social locations.

\section{Scaling Up: Mentor Program Challenges}

Some challenges are endemic to a program of this size and cast, related to both its history of successful growth over two decades in a public university setting located in a state with decreasing state funding levels for higher education and steadily rising tuition. These challenges are summarized below.

\section{Budgets, recruitment, hiring, and daily operations}

1. Securing ongoing annual budget support for hiring mentors.

2. Navigating changing employment contracts for graduate students in the Graduate Employees Union/AFT/AAUP.

3. Engaging equity and socially just practices throughout program activities (e.g., hiring, recruiting, staffing, training).

4. Staffing support and daily administration of operations. 


\section{Mentor training and scheduling}

1. Training mentors with increased expectations for the impact of their roles.

2. Scheduling mentors each term in a complex puzzle.

3. Engaging support from faculty and the institution to develop and support additional training activities (e.g., educational technology, ePortfolio, online learning, mental health and wellness resources, financial and food insecurity, Universal Design for Learning).

These challenges are not new in a dynamic university environment and within the context of increasingly underfunded public higher education. However, the Peer Mentor Program faces two issues that continue to stress the edges and scale of the program. The first is budgetary marked by increased costs for remissions, awards, and stipends for our undergraduate and graduate mentors. The second is the staffing size and capacity for the areas of the program that require additional training and support for mentors, such as online learning, ePortfolio, and University Studies learning goal updates.

Budgets and staffing capacity to deliver a high-quality program are the most significant daily challenges for the program presently and historically. With the increased demand from the 1990s to the 200os related to the SINQ courses, in particular, the growing cost and number of Graduate Mentors have specifically been an emerging concern for University Studies program leaders. Stalled growth in remissions allocations from the university in recent years compounds this budgetary problem. Moreover, university allocations have not kept pace with student demand for courses that each require a mentor.

Additionally, Portland State University graduate students voted to unionize and negotiated their first collective bargaining agreement with the University (Portland State University \& Graduate Employees Union AFT/AAUP, 2018). The new terms of graduate student employment present additional budget changes and challenges for programs like University Studies that hire large numbers of graduate students. No indication exists at this time that these increasing costs to programs will be absorbed at the institutional level. Indeed, a cross-campus solution will be needed to alleviate the situation, and, in the meantime, this budgetary crisis is the current issue most directly affecting the future stability of the Graduate Mentor program.

\section{Scaling Inward: Learning from University Studies' Teaching and Learning Community}

The successes and resilience of the Peer Mentor Program, despite these challenges, are the direct result of the ways that University Studies and its 
faculty, staff, mentors, and leadership readily embrace the program and values. Faculty, staff, and program leaders frequently participate in developing mentor resources, collaborate on assessment and research, support the director, and create training workshops for new mentors. The director encourages mentors to develop their projects and explore their identities as teachers, scholars, and learners. This sense of ownership by and across the program provides the additional logistical and professional support required for the Peer Mentor Program to work effectively at this scale. Though certain pragmatic hurdles always remain in a dynamic environment, the scaling inward of the talents and efforts of the larger University Studies community and university partners create and bind the program priorities in a sustaining way where mentors and students can thrive.

\section{Taking High-Impact Practices to Scale: Revising University Studies' Diversity Learning Goal}

As Diversity, Equity, and Inclusion Coordinator in University Studies since 2017, I (coauthor Fernández) was involved in the collaborative process of revising University Studies' diversity learning goal during the 2016-2017 academic year. In my role as coordinator, I work to move forward diversity and equity practices in University Studies, both pedagogical and administrative, as I continue to teach Freshman and Sophomore Inquiry courses.

In the following sections, I summarize the collaborative process designed by the University Studies Council (USC) and University Studies faculty to revise our 1996 Diversity of Human Experience learning goal. The USC, a constitutional committee, makes policy recommendations related to University Studies, coordinates the review of new course recommendations, and may conduct reviews or assessments of the program (PSU Faculty Const. art. IV, $\$ 4.4$ ). ${ }^{1}$ Because self-reflection is one of the dynamic qualities in University Studies, I will also summarize challenges and takeaway moments from faculty who participated in this revision process.

\section{History}

In 1996, University Studies created its four learning goals, including one addressing the diversity of human experience (White, 1994). Twenty years later, University Studies started the process of collaboratively revising the diversity learning goal. To highlight the shift in language and focus (from appreciating cultural differences to understanding power relationships, for example), the original and revised diversity learning goal appear below (University Studies Council, 2016, p. 1): 
The original learning goal: The Diversity of the Human Experience (1996)

Students will enhance their appreciation for and understanding of the rich complexity of the human experience through the study of differences in ethnic and cultural perspectives, class, race, gender, sexual orientation, and ability.
The revised learning goal: Diversity, Equity, and Social Justice (2016)

Students will explore and analyze identity, power relationships, and social justice in historical contexts and contemporary settings from multiple perspectives.

In 2016-2017, the USC developed a collaborative process to revise the 1996 diversity learning goal. The process highlights a key aspect of working in University Studies: we lean on "relationships of trust" as faculty engage in challenging conversations focused on diversity and social justice. I borrow this phrase, "relationships of trust," from my interview with Pedro Ferbel-Azcarate (Assistant Professor in Black Studies), thenchair of the USC's Diversity Subcommittee which managed the learning goal's revision process. For FerbelAzcarate, establishing "relationships of trust" with a so-called faculty of color is key to minimizing the tokenism that frequently occurs when such faculty are asked to weigh in on "diversity" matters. By centering "relationships of trust" as a fundamental practice, the USC sought not only to minimize tokenism experienced by some faculty of color but also to bring into the conversation their lived experiences:

It wasn't like we [in Black Studies and Indigenous Nations Studies] didn't have relationships of trust. So when we asked our colleagues to be at one of these [revision] meetings, they were like "of course" because I'm not being tokenized. My knowledge is actually being appreciated and valued and will go into something substantial, so I think that's good for the university. [We did not change] the language without consulting [them]. (P. FerbelAzcarate, personal communication, June 28, 2018)

In designing a collaborative revision process, the USC intentionally created two university-wide forums with University Studies faculty, Portland State University faculty and staff, and community members in April 2016. Twelve faculty members were identified for their teaching experience and authority on the diversity learning goal and were asked to present short analyses on how they pursue this goal in their curriculum while highlighting specific challenges 
relevant to their discipline. Small group discussions with other faculty, staff, and stakeholders followed, and then the whole group convened for an open dialogue. USC members collected and organized notes. A preliminary report was presented to USC at its May 2016 meeting for feedback (University Studies Council, 2016, p. 1-2). In addition to specific faculty members, the USC sought feedback that summer from the vice president for Global Diversity \& Inclusion, the executive director of the University's Cultural Resource Centers, the University Studies executive director, and the director of the School of Gender, Race, and Nations (University Studies Council, 2016, p. 2). The Faculty Senate approved the revised diversity learning goal in winter term 2017.

\section{Focus on University Studies' Diversity Learning Goal: Why Revise it for Our Students?}

More of our university students also identify as multi-ethnic and thus belong to more than one discrete cultural or ethnic group. The original diversity learning goal presented a view that "class, race, gender orientation, and ability" are singular-as opposed to intersectional and multiple experiences. In Oregon, a growing number of "multi-racial" students are coming to Portland State University from Portland Public Schools (PPS). The number and proportion of "multi-racial" students in PPS (to use their terminology) increased steadily over the last five years, from 5\% in 2010-11 to $8 \%$ in 2014-2015 (Portland Public Schools, 2004, p. 1). At Portland State University, the number of "multi-ethnic" students (to use the University's terminology) also increased for the past two years. For the 2016-2017 academic year, 5.7\% of University students self-identified as "multi-ethnic" compared to $6.0 \%$ for the $2017-2018$ academic year ("Culturally responsive \& inclusive curriculum," 2018; "Profile," 2018). In University Studies specifically, for last fall $2017,10 \%$ of FRINQ and $9 \%$ of SINQ student students identified as falling into the multi-ethnic category (C. Carpenter, personal communication, November 27, 2018). The increased presence of "multi-racial" students in Oregon is, of course, a reflection of national trends that track the rise of multiethnic families across the United States (Livingston, 2017).

\section{Focus on University Studies' Diversity Learning Goal: Why Revise it for our Faculty?}

In reviewing public and private feedback about revising the 1996 learning goal, faculty from a variety of ethnocultural backgrounds and academic disciplines remarked that they wanted to move away from the goal's language of appreciation (i.e., "students will enhance their appreciation of"). As an immigrant from Costa Rica, I found the language of appreciation as distancing students and 
faculty members from an active engagement with their "positionality" in the classroom, in society, and with cultures unlike their own (Alcoff, 1988). Instead of "appreciating" other cultures, the revised diversity learning goal values the exploration and the analysis of nothing less than identity (meaning that faculty members, students, and community partners are asked to explore their positional identities), power relationships, and social justice from multiple perspectives and historic times.

Faculty also wanted to move toward examining power as a fundamental practice in understanding diversity. In remarks to the USC, Dr. Alma Trinidad (Social Work and University Studies, and an author in this volume) reminded the Council how self-reflection makes salient the social identities of faculty members and impacts their curriculum:

The instructor needs to be a couple of steps ahead of students with regard to critical consciousness and engagement (i.e., "Me" work) and be aware of how our own social identities influence our curriculum. We are in control of the learning environment and need emotional stamina to be able to have these difficult and sometimes draining conversations as well as an awareness of our students' experience. (University Studies Council, 2016, p. 3)

Indeed, faculty members seeking to engage in socially-just teaching practices must consider their social location in the classrooms with students and community partners and reflect on how their social location impacts the creation of course content and classroom pedagogies.

\section{Scaling Inward: Reflecting on Current Challenges and Opportunities}

In University Studies, challenges are opportunities to reflect, collaborate, and acknowledge the causes of those challenges. At this writing, the revised the Diversity, Equity, and Social Justice learning goal is less than two years old. The work of implementing any learning goal is an ongoing process-let alone one addressing diversity, equity, and social justice. Obviously, implementation challenges are not unique to University Studies or the University. In the table below, I share how, through my diversity coordinator role, I approach these implementation challenges while underscoring that University Studies' teaching and learning community encourages faculty, staff, and program leaders to share responsibility in addressing them, too. 
Addressing Our Pedagogy and

Curriculum

1. Faculty asking the following: "Tell me what I am doing right/wrong in my course."

2. Faculty expressing discomfort regarding how to connect the revised diversity learning goal to what they already teach and how they teach it.

3. Making sure all syllabi in University Studies include the updated 2016 diversity learning goal.

4. Adjunct faculty who "inherit" course materials not aligned with the 2016 diversity learning goal days before the start of the term

5. Teaching to this learning goal in online classrooms.

Clarifying the Role of the Program's Diversity Coordinator Faculty and staff asking the diversity coordinator to be the program's "expert" on various on-campus resources addressing diversity (for example, Disability Resource Center, Queer Resource Center, Women's Resource Center).
- Continue to invite self-reflection. To change what and how we teach, we need to examine ourselves.

- Continue to message that the work of understanding our revised diversity learning goal is an ongoing communal and personal effort and not the sole responsibility of a diversity coordinator.

- Acknowledge that the revised diversity learning goal may cause discomfort.

- After acknowledging discomfort, ask faculty members to envision that this learning goal requires a different kind of teaching and exposure to a different sort of curriculum.

- Organize dialogues during yearly faculty orientations to address the revised diversity learning goal.

- From 2016--2018, University Studies faculty participating in fall orientation are asked to share-in small and large group discussions-how they teach to the revised diversity learning goal.

- Acknowledge the precarity (financial, access to healthcare, for example) that our adjunct faculty experience.

- Continue to work with full-time faculty so materials they share with new faculty align with the revised diversity learning goal.

- Ask online faculty to share how they teach to this learning goal.

- Continue to engage all faculty and staff in speaking about diversity-related issues in classrooms and meetings, for example, and to embrace "cultural humility" (Hook, Davis, Owen, Worthington Jr., \& Utsey, 2013) and reflect on their "positionality" when doing so (Alcoff, 1988).

- Address moments of tokenism when the diversity coordinator is asked to be the "expert" on various facets of "diversity." 


\section{Scaling Up and Scaling Inward: Sharing Revision Process Takeaways}

During the summer of 2018, I interviewed colleagues who participated in the revision process. I asked them what "Aha!" moments they would share with colleges and universities that are considering revising a diversity learning goal. In the table below, I summarize my "Aha!" moments and also credit specific faculty for their input.

\section{Table 3 | Sharing Takeaways: The Process of Revising a Diversity Learning Goal}

\section{Initiation Phase}

1. Conduct an environmental diversity scan of your university.

2. Who is already teaching to a diversity learning goal?

3. Who are experts in disciplines linked to culturally-inclusive practices?

4. In the administration, "who are the leaders and supporters of culturally-inclusive practices and leadership styles" (C. Carmina Gómez, personal communication, July 2, 2018)?

5. Commit to developing "relationships of trust" among faculty and administrators while recognizing that such relationships require time and must be genuine (P. Ferbel-Azcarate, personal communication, June 28, 2018).

6. Emphasize a sense of urgency so that faculty consider the curricular change as more than a bureaucratic process. Ask faculty: why is it urgent to change the curriculum for our students and ourselves?

\section{Planning Phase}

1. Invite faculty from all disciplines, and not only those fields customarily associated with diversity, equity, and social justice.

2. Ask a variety of stakeholders not often linked with curricular changes to be part of the process, including librarians (K. Willson-St. Clair, personal communication, June 28,2018 ), academic professionals, and student affairs administrators

3. Create opportunities for minority faculty to reflect both personally and academically on the institution's commitment to diversity at all levels and, if available, diversity learning goals.

4. Invite and honor student voices; prepare future leaders to work collaboratively by educating our undergraduate and graduate students in collaborative revision processes. 


\section{Implementation Phase (on-going)}

1. Expect that some faculty members may experience "white fragility"; provide sample readings (DiAngelo, 2018) and workshops on "white fragility."

2. Incorporate the revised learning goal as part of inclusive hiring practices when candidates apply for teaching positions.

3. Consider change across academic units, and "imagine the power of introspection and communal sharing" if a diversity learning goal in one academic unit might inform another (P. Ferbel-Azcarate, personal communication, June 28, 2018).

4. Be committed to assessing the institutions' diversity learning goal on an ongoing basis.

\section{Scaling Inward: Revising a Diversity Learning as "A Practice of Freedom"}

I believe that University Studies' commitment to reflect and share responsibility for the revision of this diversity learning goal moves students and faculty members closer to experiencing "education as the practice of freedom" (Freire, 1970/2003, p. 81). Students and faculty members thus become "jointly responsible for a process in which all grow" (p. 80). Translating the diversity learning goal into lived experiences in classrooms will test University Studies' resolve to scale up and scale inwardly culturally-inclusive curriculum and pedagogy across the Program. At the end of the 2017-2018 academic yearand as part of our ongoing assessment of our revised diversity learning goalour FRINQ students were asked: "What did you learn from those [classroom] activities related the new [diversity learning] goal?” From a thematic analysis of 200 randomly-selected comments in FRINQ, one first-year student offered this reflection about the "power relationships" wording in our revised diversity learning goal:

Identity has been big in the past and is an even bigger topic today. Power relations are changing what they appear as, but they are still the same kind of relationships. This [sic] goes for social justice as well; society is changing, but there are still the same kinds of issues, whether or not [they] appear in the same forms or not. (Carpenter, 2018)

The comment above indicates that our students understand the complex interplay between power, identity, and social justice. With the guidance of University Studies' director of assessment, a team of our faculty members 
already revised the goal-associated learning rubric that the Program will use to assess FRINQ ePortfolios, furthering embedding the revised diversity learning goal and our engagement with it across the program.

As program leaders in this active, relational teaching and learning community, the coauthors demonstrated that three dynamic qualities contributed to past and ongoing scaling up efforts of its programs and curricular initiatives: (1) focus on University Studies' aspirational goals; (2) interplay between scaling up and scaling inward; and (3) collaborative and engaged leadership when revising, for example, a diversity learning goal. The findings suggest that, contrary to notions that running a program of this scale only addresses budgets and staffing needs, University Studies adapts to change because it built a dynamic and aspirational framework across its general education program. To be clear, these findings and University Studies' ongoing approach to taking high-impact practices to scale are a result of its more than twenty-year history and specific challenges University Studies experiences at Portland State University. Despite the complexity of bringing high-impact practices to scale at a large state university, opening new lines of reflection, action, and inquiry allows University Studies students, faculty, and leaders to be part of a general education program intentionally evolving towards socially just and inclusive ends.

ÓSCAR FERNÁNDEZ is a faculty member in University Studies and serves as its Diversity, Equity, and Inclusion Coordinator. He specializes in inter-American studies, literary theory, and the intersection of culture, sexuality, and representations of disease in Iberoamerican literature. He earned a PhD in Comparative Literature from The Pennsylvania State University.

DANA LUNDELL is Program Director for Peer Mentor Programs in UNST at Portland State University. Her teaching, administration, and research for over two decades have focused on mentoring, diversity and inclusion, innovative curriculum, student development, and writing in higher education. She has a PhD in Curriculum and Instruction and an MA in English from the University of Minnesota-Twin Cities.

SEANNA KeRRIGAN, Ed.D. has served for over two decades as Capstone Program Director at Portland State University. She collaborates with scores of faculty, students, and community organizations to implement the nation's largest Capstone program. She is committed to reciprocity and equity. Her work and scholarship focus on the transformative effect of community-based learning pedagogy on participants.

\section{NOTE}

1. The authors would like to thank Pedro Ferbel-Azcarate (Portland State University, Assistant Professor, Black Studies Department), Cynthia Carmina Gómez (Portland State University, Executive Director, Cultural Resource Centers), and Kimberly Willson-St. Clair (Portland State University, 
Assistant Professor, Reference \& Instruction Librarian) for meeting with co-author Fernández and sharing University Studies Council reports to the Faculty Senate.

\section{WORKS CITED}

Agee, K., \& Hodges, R. (2012). Handbook for training peer tutors and mentors. Mason, OH: CENGAGE Learning.

Alcoff, L. (1988). Cultural feminism versus post-structuralism: The identity crisis in feminist theory. In Minnich, E., O'Barr, J., and Rosenfield, R. (Eds.), Reconstructing the academy: Women's education and women's studies (pp. 405-36). Chicago and London: University of Chicago Press.

Astin, A. W. (1997). What matters in college: Four critical years revisited. San Francisco, CA: JosseyBass.

Capstone Program. (2018). [University Studies: Capstone end-of-the-term survey, spring 2018]. Unpublished raw data.

Carpenter, R. (2018, October). Diversity, equity, \& social justice FRINQ student comments: Thematic analysis of 200 randomly selected FRINQ student comments (out of 873). University Studies, Portland State University. Presented at University Studies' fall 2018 faculty orientation.

Collier, P. (2015). Developing effective peer student peer mentoring programs: A practitioner's guide to program design, delivery, evaluation, and training. Sterling, VA: Stylus Publishing.

— (2017). Peer mentoring: A tool for serving the diverse needs of 21st century college students. Metropolitan Universities, 28(3), 3-8.

DiAngelo, R. (2018). White fragility: Why it's so hard for white people to talk about racism. Boston: Beacon Press, 2018.

Freire, P. (2003). Pedagogy of the oppressed. (Myra Bergman Ramos, Trans.). New York, New York: Continuum 2003. (Original work published 1970.)

Ho, A., \& Wolfe, K. (2016). High impact work for self and society: Community engaged signature work. Diversity \& Democracy, 19(4), 4-8.

Hook, J. N., Davis, D. E., Owen, J., Worthington Jr., E. L., \& Utsey, S. O. (2013). Cultural humility: Measuring openness to culturally diverse clients. Journal of Counseling Psychology, 60(3), 353-66. DOI: 10.1037/a0032595.

Kerrigan, S., Gelmon, S., \& Spring, A. (2003). The Community as Classroom: Multiple Perspectives on Student Learning. Metropolitan Universities. 14 (3), 53-67.

Kerrigan, S., \& Jhaj, S. (2007). Assessing general education capstone courses: An in-depth look at a nationally recognized capstone assessment model. Peer Review, 9(2): 13-16.

Komives, S.R., Dugan, J. P., Owens, J. E., Slack, C. Wagner, W., \& Associates. (2011). The handbook for student leadership development (2nd ed.). San Francisco: Jossey-Bass.

Livingston, Gretchen. (2017). The rise of multiracial and multiethnic babies in the U.S. Pew Research Center: FACT/TANK. Retrieved from http://www.pewresearch.org/fact-tank/2017/06/06/therise-of-multiracial-and-multiethnic-babies-in-the-u-s/.

Mitchell, T. D. (2008). Traditional vs. critical service-learning: Engaging the literature to differentiate two models. Michigan Journal of Community Service Learning, 14, 50-65.

Portland Public Schools/System Planning and Performance. (2015, March). Research brief: "Multiracial" students at a glance. Portland, OR: Author. Retrieved from https://www.pps. net/cms/lib/OR01913224/Centricity/Domain/207/multiracialbrief20150825.pdf. 
Portland State University (PSU) Faculty Const. art. IV, § 4.4.

Portland State University. (1998, January). University Studies 1994-1997: A progress report. Retrieved from https://www.pdx.edu/sites/www.pdx.edu.unst/files/University\%20Studies1994-1997 ProgressReport.pdf.

Portland State University \& Graduate Employees Union AFT/AAUP. (2018, March 28). Collective Bargaining Agreement between Graduate Employees Union AFT/AAUP and Portland State University, Portland, OR. Retrieved from https://www.pdx.edu/academic-affairs/sites/ www.pdx.edu.academic-affairs/files/PSU\%20130017\%20P5\%20CBA\%20Packets\%20PROOF \%20for\%20Website\%20Approved\%204.11.2018.pdf.

Portland State University Library. (2018). Culturally responsive \& inclusive curriculum resources: Student demographics. Retrieved from https://guides.library.pdx.edu/c.php? $g=527355 \& p=5313778$.

Portland State University. (2018). Profile. Retrieved from https://www.pdx.edu/profile/snapshotportland-state

Ray, J., \& Kafka, S. (2014, May 6). Life in college matters for life after college. Gallup. Retrieved from http://news.gallup.com/poll/168848/life-college-matters-life-college.aspx?version=print

Rivard, R. (2014, May 6). Graduates' well being. Inside Higher Education. Retrieved from https:// www.insidehighered.com/news/2014/05/06/gallup-surveys-graduates-gauge-whether-andwhy-college-good-well-being.

Smith, B. (2013). Mentoring at-risk students through the hidden curriculum of higher education. Lanham, MD: Lexington Books.

Tinto, V. (1994). Leaving college: Rethinking the causes and cures of student attrition (2nd ed.). Chicago: University of Chicago Press.

University Studies Council. (2016, November 30, 2016). University Studies Council report to PSU Faculty Senate: A revised diversity learning goal proposal. Portland State University, Portland, OR: Author.

University Studies Program. (2011, Fall). 2010-2011 University Studies annual assessment report. Retrieved from https://www.pdx.edu/unst/sites/www.pdx.edu.unst/files/10-11\%20Mentor\% 20Annual\%20Report.pdf.

University Studies Program. (2011, Summer). The impact of peer mentoring at Portland State University: A report from University Studies. Retrieved from www.pdx.edu/unst/sites/www. pdx.edu.unst/files/FINAL\%20Report\%200n\%20UNST\%20Peer\%20Mentoring\%202011-1.pdf Weiston-Serdan, T. (2017). Critical mentoring: A practical guide. Sterling, VA: Stylus Publishing.

White, C. R. (1994). A model for comprehensive reform in general education: Portland State University. The Journal of General Education, 43(3), 168-229. 